\title{
The female condom in Zimbabwe: The interplay of research, advocacy, and government action
}

Population Council

Follow this and additional works at: https://knowledgecommons.popcouncil.org/departments_sbsr-hiv

Part of the Demography, Population, and Ecology Commons, International Public Health Commons, and the Public Health Education and Promotion Commons How does access to this work benefit you? Let us know!

\section{Recommended Citation}

"The female condom in Zimbabwe: The interplay of research, advocacy, and government action," Horizons Research Summary. Washington, DC: Population Council, 1999. 
Refining the response to HIVIAIDS through global operations research

The PSI/Zimbalowe "care" soccer team belped promote the female condom at large sports events.
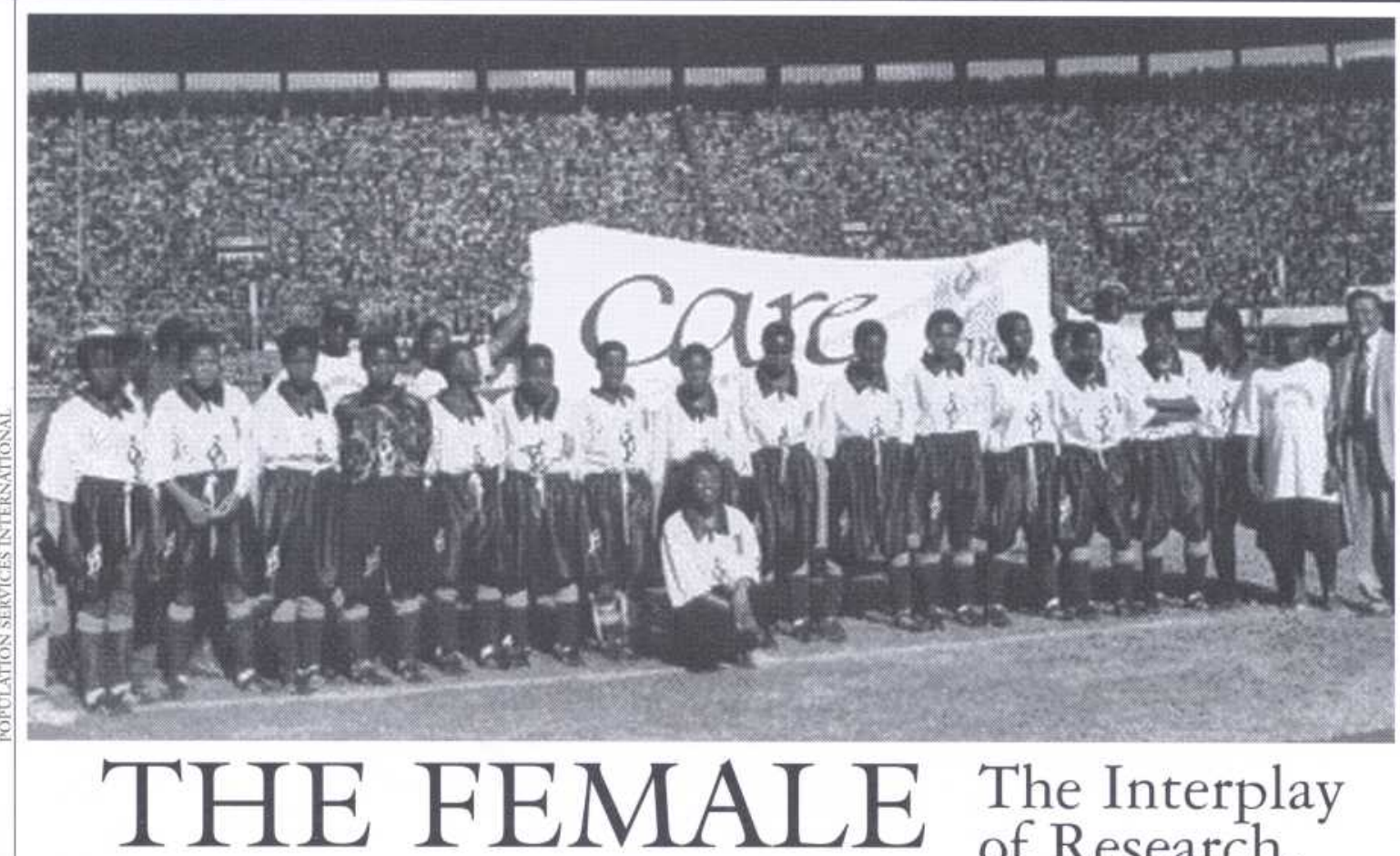

The Interplay of Research, CONDOM

IN

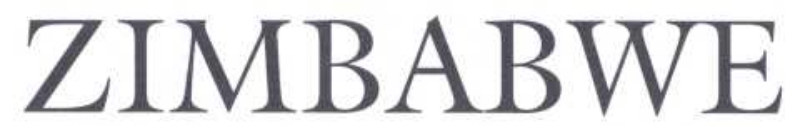

During the past decade, a significant increase in reported cases of HIV/AIDS in Zimbabwe prompted the government, local organizations, and international donors to intensify prevention efforts. As part of this response, in November 1996 Zimbabwe's National AIDS Coordinating Programme (NACP) invited Population Services International (PSI) to launch a social marketing program to promote the female condom, making this protective device widely available for the first time in Africa.

\section{Advocacy, and \\ Government Action}

But the campaign for the female condom actually began several years before the government's bold initiative. Awareness of the female condom and its value in preventing HIV transmission had grown among Zimbabweans since the early 1990 s, due largely to the efforts of women's organizations to ensure its availability at an affordable price. After an acceptability study showed that Zimbabwean women and men liked using the female 


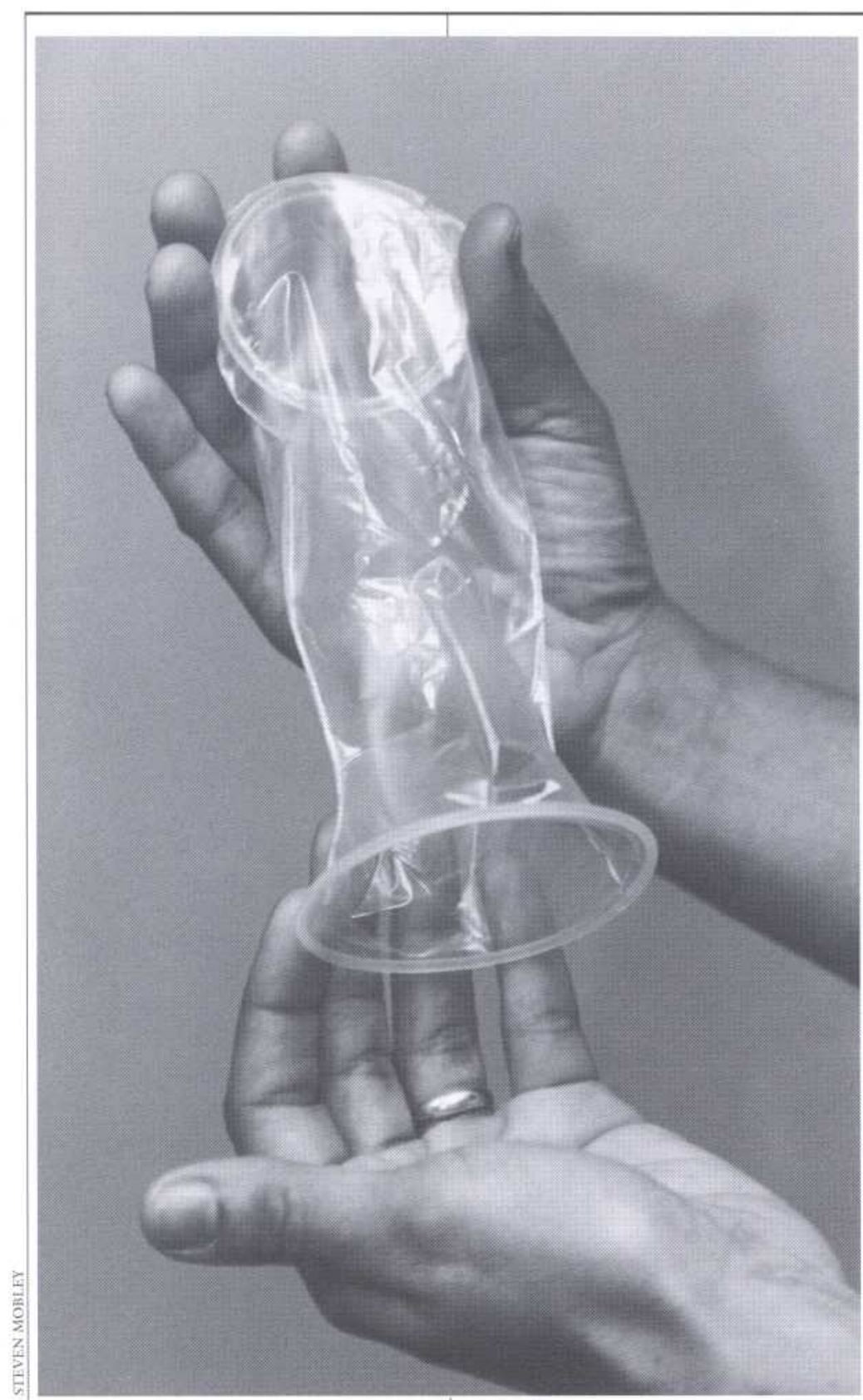

condom, leaders of these organizations encouraged public discussion and media attention, which helped pave the way to approval and introduction of the device.

This summary presents the findings of a case study conducted by Grace Osewe and sponsored by the Population Council's HIV/AIDS operations research Horizons Project. The study reviewed the social and political factors that led to government device but also the critically important research and advocacy efforts that led to widescale public support for it.

\section{Women's Vulnerability}

HIV/AIDS continues to have a devastating impact on Zimbabwe. With nearly 25 percent of the adult population infected, the country has among the highest total number of infections in subSaharan Africa (UNAIDS/ WHO 1998). Projections for the year 2005 estimate that 1.2 million Zimbabweans will have died from the disease and that nearly one million children will lose one or both parents to it (NACP 1998).

Zimbabwean women have been struck especially hard. In the 15- to 19-year-old age group, six times more women than men are infected (NACP 1998). This gap is largely caused by cultural and gender norms that relegate most decision-making within relationships-including sexual relations - to men. Women are rarely able to refuse sex or to demand protective measures such as male condom use when they suspect their partners of infidelity (Ray et al. 1998). Female subordination is reinforced by a culture in which marriage defines a woman and her status in the community (Win 1998).

Thus, women are often forced to risk "biological death" from AIDS to avoid the "social death" and poverty caused by divorce or abandonment (Bassett and Mhloyi 1991).

Given the scarcity of prevention efforts targeted to women other than sex workers, in the early 1990 s
T orizons is a five-year (1997-2002) global operations research project designed to - Identify components of effective HIV/AIDS programs and policies.

- Test potential solutions to improve prevention, care and support programs, and service delivery.

- Disseminate and utilize findings with a view toward replication and scaling up of successful interventions.

\section{Horizons is} directed by the Population Council under a cooperative agreement with the U.S. Agency for International Development and is one component of a larger USAID initiative to reduce HIV transmission and mitigate its impact in developing countries. Horizons partners are the International Center for Research on Women (ICRW), the Program for Appropriate Technology in Health (PATH), the International HIV/AIDS Alliance, the University of Alabama at Birmingham, and Tulane University. 
women's organizations began to develop educational programs to increase women's knowledge about HIV/AIDS and other sexually transmitted infections (STIs) and to provide support to enable them to protect themselves. In turn, women expressed their inability to discuss safer sex in their relationships. In a classic bottom-up approach, women who were being reached by such NGOs as Women's Action Group (WAG) and Women and AIDS Support Network (WASN) consistently asked for something they could use to protect themselves if a partner was unwilling to use the male condom. An emerging new productthe female condom-had the potential to fill that need, but little research had been done on its viability.

\section{The Acceptability Study}

In 1993, Drs. Sunanda Ray and Mary Bassett, two researchers from the University of Zimbabwe's Department of Community Medicine and members of

\section{"The female condom will}

\section{add to the choices that men} and women have to protect themselves against HIV."

Dr. Sunanda Ray, CHIEF RESEARCHER FOR THE ACCEPTABILITY STUDY AND CO-FOUNDER OF WASN
WASN, received funding from the World Health Organization (WHO) to conduct an acceptability study of the female condom in Zimbabwe. The researchers sought to determine whether the product was a viable alternative for Zimbabwean women, given that the device is not likely to be used without the consent of male partners.

The study (Ray et al. 1995) was conducted with three groups of women volunteers: sex workers, urban women attending a family planning clinic, and rural peasant women, all either married or in long-term relationships. Those who enrolled were interviewed at baseline and supplied with female and male condoms and trained in how to use them. Two follow-up interviews were conducted with participants, during which they received additional condoms. Workshops in both communication skills (how to introduce the female condom to a partner) and technical skills (how to use it correctly) took place during the course of the study. Participants also joined focus group discussions at the end of the second follow-up. Out of an initial enrollment of 221 women, 193 women remained at the first follow-up and 93 women at the second.

Findings from the first follow-up revealed that most of the women in all three groups and their male partners liked the female condom very much, in fact preferring it to the male condom. Less than 10 percent did not like the device. Other findings included the following:

- Because most of the women did not feel empowered to negotiate male condom use with their partners, the female condom offered a measure of control they hadn't experienced before.

- Women felt better protected with female condoms because of their strength and resistance to breaking.

- Using the device became easier with practice, despite such complaints as difficulty of insertion and discomfort.

Participants were asked how their male partners felt about the female condom. Most men were reported to like the device, for a number of reasons:

- It could be inserted in advance of the sex act, with no interruption of intimacy.

- They did not have to have a full erection before intercourse.

- The device did not constrict the base of the penis, like male condoms.

- They did not have to withdraw from the vagina immediately after ejaculation.

Once the study was completed, the research team organized feedback sessions to discuss results with the NACP and other health officials, the Zimbabwe National Family Planning Council, WASN, AIDS research groups, and others. Major issues included the feasibility of offering the female condom as a mainstream method of prevention, given its prohibitively high cost of US\$1.25 each, and the ethics of raising women's expectations with no guarantee that the product would be available.

The researchers argued that not just Zimbabwe but the entire developing world, where 90 percent of HIV infection occurs, must join with wealthier nations to seek 


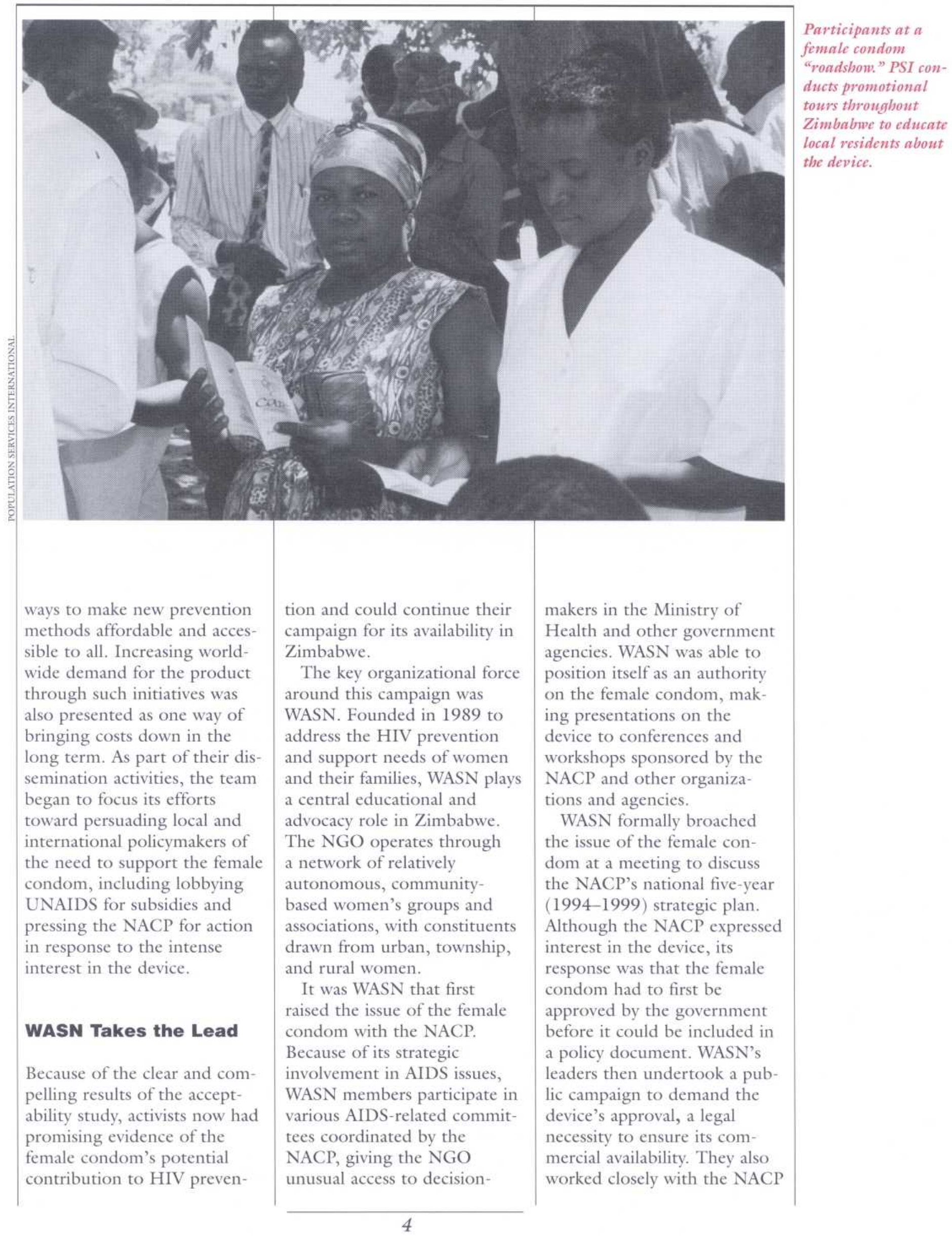


and UNAIDS to discuss how

best to resolve the problem of the device's high cost and to

explore opportunities for subsidies.

The campaign evolved into a multifaceted strategy to build support. An important element was community mobilization, achieved by engaging the women who had participated in the acceptability study to educate other women in rural areas and to encourage them to ask their health providers about the female condom. As word of the device spread throughout communities and within the health system, demand grew from the grassroots that ultimately reached the NACP.

Press coverage was an early catalyst for this growing national discussion. In April 1995 , WASN displayed and discussed the female condom at the annual Zimbabwe Trade Fair held in Bulawayo, which led to considerable media attention and numerous interviews with reporters. At the 1995 United Nations Conference on Women held in Beijing, China, Priscilla Misihairabwi, then director

\section{"The petition put a face on the female condom campaign."}

Priscilla Misihairabwi, FORMER DIRECTOR OF WASN

of WASN, presented a paper on the female condom that included the findings from the Zimbabwe acceptability study. The Reuters News Agency reported the story around the world, and the coverage generated even more interest in the device in Zimbabwe. After the Reuters article appeared, national media outlets turned to WASN leaders for information and commentary about the female condom. WASN was repeatedly invited for interviews by all four national radio stations and the national television system, appearing on talk shows and phone-in programs. Both local and national magazines and newspapers published articles about the device.

To gain allies and avoid confrontation, WASN characterized the female condom as a product for "monogamous" women placed at risk by their partners, rather than a product for adulterous relationships or premarital sex. This made it difficult for church groups or other antagonists to campaign strongly against the device.

Support for the female condom grew among the country's leadership, and discussion of the device soon entered the political arena. At the national ruling party's annual assembly in 1996, Deputy Minister of Health Tsungirirai Hungwe addressed the gatheringwhich included President Robert Mugabe-about the female condom and the need to make it available. Although Minister of Health Dr.

Timothy Stamps was initially opposed to the female condom, he soon became a supporter.

To incorporate women's voices into the campaign,
WASN launched a petition drive promoted by an extensive media campaign. It solicited the invaluable support of the community-based women's groups involved in the acceptability study as well as other women's organizations-among them, Women in Law and Development in Africa, WAG, and the

Zimbabwe Women's Resource Center-in circulating the petition at meetings, workshops, and other gatherings. By World AIDS Day

(December 1) 1996, 30,000 signatures had been collected.

But even before the petition drive ended, the campaign was victorious. In September 1996, Zimbabwe's Medical Control Council approved the female condom for use. The focus immediately shifted to development of two complementary distribution systems: within the public sector, at no cost; and a private sector social marketing program subsidized by international donors, to be added on to one that already existed for the male condom. The NACP launched both efforts in July 1997.

\section{Marketing the Female Condom}

A USAID-funded social marketing program for the male condom had operated in Zimbabwe since the late 1980 s. Under the auspices of the NAPC, in 1996 Population Services International (PSI) was chosen to implement a new program for the male condom with a focus on HIV/STI prevention, with support from both USAID and its British counterpart, the Department for International Development. Aware of the 


\section{Female Condom Sales: July 1997-Nov 1998}

(in thousands)

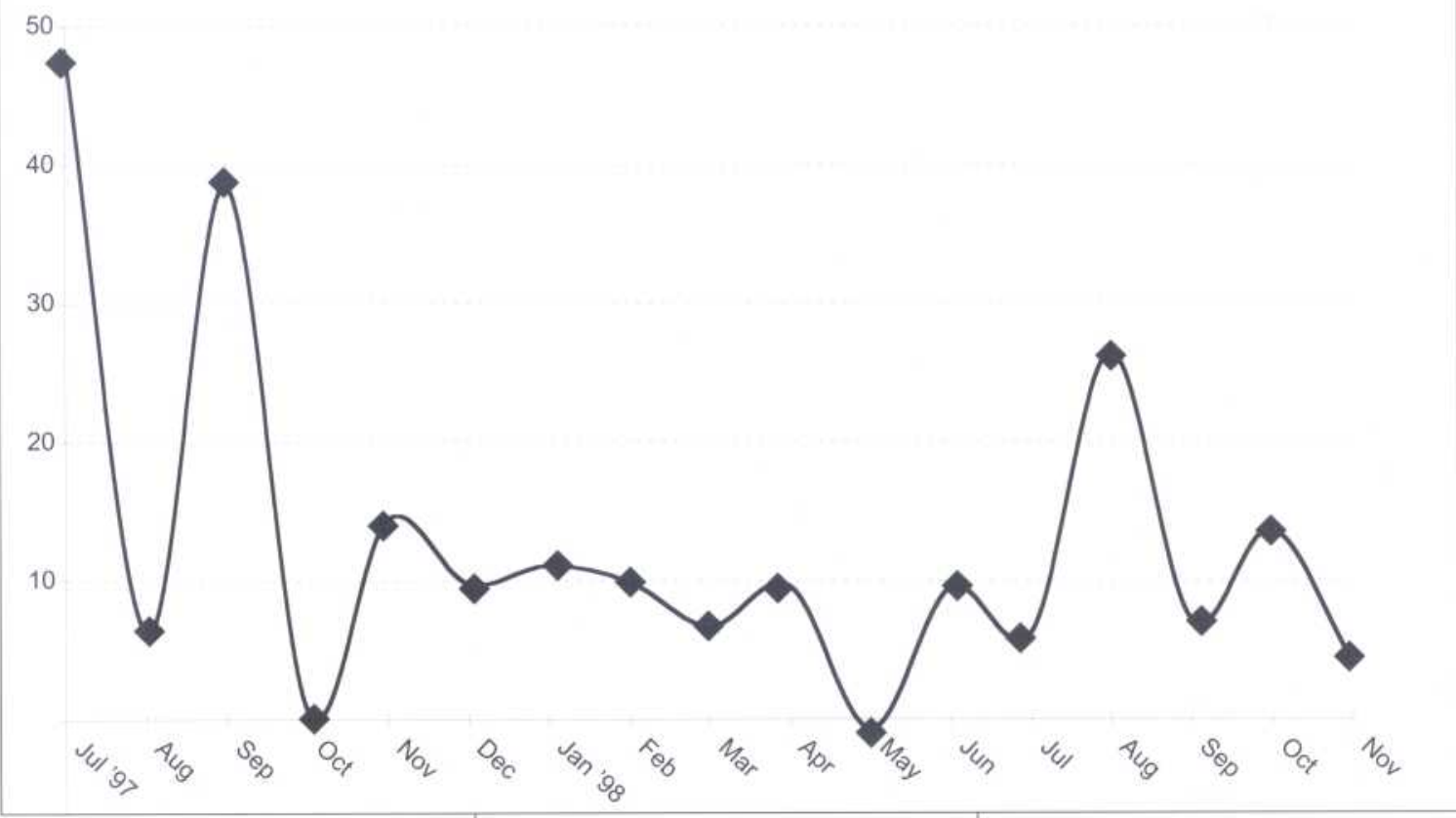

intense interest in and lobbying for the female condom, PSI proposed incorporating the device into its program, to which the donors and the NACP agreed.

As part of program activities, PSI formed a social marketing advisory group (SMAG) composed of important stakeholders, including women's groups, the press, university departments, government health agencies, donors, and commercial and distribution interests.

SMAG members were consulted on a one-on-one basis where appropriate, and collectively to discuss market research issues and results.

Research conducted by PSI led to the following marketing considerations:

- Due to the stigma attached to the male condom, the female condom needed to be perceived as focused on a general theme of "caring," as opposed to only HIV/STI prevention.

- Since the device would be more favorably viewed in a medical context, it should be placed in the health product section of retail outlets.

- The "clean," hygienic aspect of the female condom was important to highlight and would help reduce the social stigma attached to condoms.

- An emphasis on family planning, as opposed to HIV/STI prevention, would help women with the negotiation process, by deflecting trust and fidelity issues.

Consultative sessions with focus groups and SMAG members led to the choice of care contraceptipe sheath as the product's name, consistent with the need to address the caring, family planning, and hygiene aspects, and to counter the stigma attached to the word "condom." The final product positioning message became: "care contraceptive sheath is a hygiene product that provides a new choice in caring pleasure." Decisions about packaging and merchandising design and placement supported this message. Donor subsidies made it possible for PSI to set an affordable price of Z\$3

(US\$.30) for a packet of two condoms.

Promotional activities included a massive training initiative directed at the medical profession to dispel myths about the product, distribute information, and reinforce the marketing message (for example, that the device be referred to as the care contraceptive sheath, not the "female condom"). Pharmacists, pharmacy staff, public clinic staff, dispensing doctors and nurses, and wholesale pharmaceutical distributors were visited on
Social marketing: how does it work?

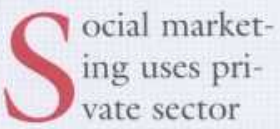
marketing methodologies to package, promote, and distribute socially beneficial products and services, often at subsidized prices. Products that have been socially marketed include male condoms and other contraceptives, oral rehydration solutions to treat diarrhea, mosquito nets to combat malaria, and solar ovens to lessen dependence on wood for cooking. 
Young shoppers at a grocery store in Harare, Zimbabwe, learn about the female condom from a field promoter:

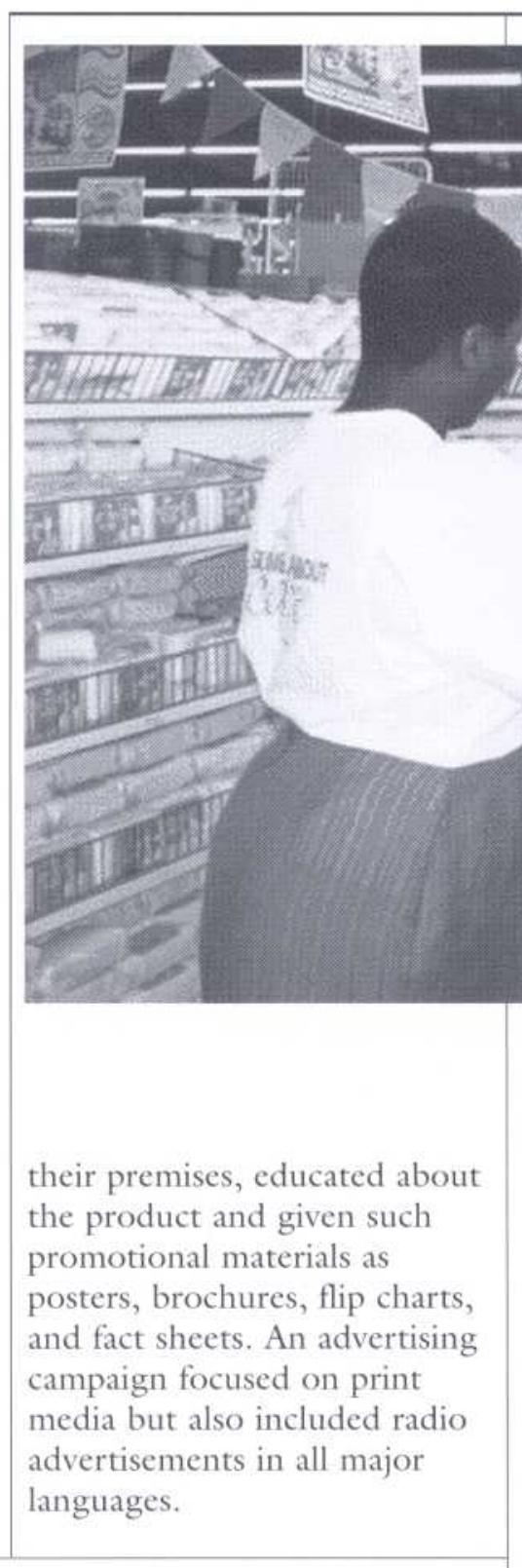

\section{"The best intervention is holistic empowerment, of which the female condom is just one part."}

Dr. Marvellous Mhloyi, CENTRE FOR POPULATION STUDIES, UNIVERSITY OF ZIMBABWE
In the first three months, sales of the sheath exceeded the annual sales projection of 80,000 condoms, requiring PSI to order extra stock. However, sales declined significantly after this introductory peak, dropping 53 percent from the first six-month sales period (July-December 1997) to the next (January-July 1998 ). This trend is very different from sales of the male condom in Zimbabwe, which have experienced steady growth since the product's relaunch in January 1998. PSI believes that the leveling off of sales may be attributable to the end of the novelty trial phase after November 1997.

Overall, the social marketing project has had a significant impact in Zimbabwe by making the female condom available and relatively accessible, especially in the urban areas where most of the sales outlets are located. It has increased media information about the female condom in Zimbabwe and enhanced its understanding and acceptance by the public.

\section{Conclusions}

The decision by the government to make the female condom available in Zimbabwe illustrates the critical importance of research, education, and advocacy. It also highlights the role that women's organizations can play in educating and influencing policymakers who make decisions about the introduction of new technologies and resource allocation.

Despite the successful introduction of the female condom, a number of questions have emerged that have implications for its potential contribu- 


\section{(2) Population Council}

tion to HIV/STI prevention in Zimbabwe. These concern how the product is introduced, with whom and how often it is used, and whether it is being substituted for male condoms or being used by women who could not negotiate male condom use. Current research being supported by Horizons and other research projects will provide important information on use patterns, negotiation, continuation, and method substitution. These data will be critical for future decisions about targeting, complementary educational activities to maximize use, and the allocation of resources for further educational and promotional activities.

- This summary is based on a report prepared by Horizons consultant Grace Osewe. Other contributors to this summary are Ellen Weiss (Horizons) ICRW) and Steven Mobley (Horizons/PATH).

\section{References}

Bassett, Mary T. and Marvellous Mhloyi. 1991. "Women and AIDS in Zimbabwe: the making of an epidemic," International Journal of Health Services 21(1): 143-156.

\section{NACP. 1998. HIV/AIDS in}

Zimbabwe-Background

Projections Impact Interventions. Harare: Ministry of Health and Child Welfare of Zimbabwe.

Ray, Sunanda, Mary Bassett, Caroline Maposhere, Portia Manangazira, Jo Dean Nicolette, Roderick Machekano, and Josephine Moyo. 1995.

"Acceptability of the female condom in Zimbabwe: positive but male-centred responses," Reproductive Health Matters 5: 68-79.

Win, Everjoice J. 1998. A Case Study of the Zimbabwe Inheritance Rights Campaign: 1989-1996. Global Women and Politics Program. Washington, DC: The Asia Foundation.

UNAIDS/WHO. 1998. Report on the Global AIDS Epidemic, June 1998.
This publication was made possible through support provided by the Office of Health and Nutrition, Global Burcau, U.S. Agency for International Development, under the terms of Grant No. HRN-A-00-97-00012-00. The opinions expressed herein are those of the author(s) and do not necessarily reflect the views of the U.S. Agency for International Development.

\section{Hgrizons र}

4301 Connecticut Avenue, NW Suite 280

Washington, DC 20008

Telephone 202-237-9400

Fax 202-237-8410

Email horizons@pcdc.org

www.popcouncil.org

Printed on recycled paper
The Population Council is an international, nonprofit, nongovernmental institution that seeks to improve the wellbeing and reproductive health of current and future generations around the world and to help achieve a humane, equitable, and sustainable balance between people and resources. The Council conducts biomedical, social science, and public health research and helps build research capacities in developing countries. Established in 1952, the Council is governed by an international board of trustees. Its New York headquarters supports a global network of regional and country offices.

- Copyright (1999 The Population Council, Inc. 